\title{
Religião no contexto universitário: uma pesquisa entre estudantes de Ciências Sociais e Psicologia da UFU
}

\author{
Claudia Swatowiski* \\ Dayane Silva** \\ Otávio Alvarenga***
}

\begin{abstract}
Resumo
Neste artigo, propomo-nos a delinear o perfil religioso de estudantes de graduação dos cursos de Ciências Sociais e Psicologia da Universidade Federal de Uberlândia (UFU), Minas Gerais, e compreender a relação que esses jovens estabelecem com a dimensão religiosa ao longo de suas trajetórias acadêmicas. Isso inclui identificar posicionamentos em torno de questões que envolvam o religioso em cada formação disciplinar, as relações que se configuram no ambiente universitário e o contexto sociocultural ampliado em que nossos interlocutores se inserem.
\end{abstract}

\section{Palavras-chave}

Religião. Juventude. Universitários. Ciências Sociais. Psicologia.

\begin{abstract}
In this article, we propose to delineate the religious profile of students in the graduation courses of Social Sciences and Psychology at the Federal University of Uberlândia (UFU), in Minas Gerais, and to understand the relation these young people established with the religious dimension throughout their academic trajectories. This includes identifying positions taken in issues that involve the religious in each disciplinary degree, the relationships configured in the university environment and the broad sociocultural context in which our interlocutors are inserted.
\end{abstract}

\section{Keywords}

Religion. University Students. Social Sciences. Psychology.

\footnotetext{
* Claudia Swatowiski é antropóloga e professora do Instituto de Ciências Sociais da Universidade Federal de Uberlândia. E-mail: swatowiski@hotmail.com .

** Dayane Silva é graduanda em Psicologia pela Universidade Federal de Uberlândia.

*** Otávio Alvarenga é graduado em Ciências Sociais pela Universidade Federal de Uberlândia.
} 


\section{Introdução}

Neste artigo, propomo-nos a delinear o perfil religioso de estudantes de graduação de dois cursos da grande área das Ciências Humanas - Ciências Sociais e Psicologia - da Universidade Federal de Uberlândia (UFU), Minas Gerais, e compreender a relação que esses jovens estabelecem - ou "desestabelecem" - com a dimensão religiosa ao longo de suas trajetórias acadêmicas. Isso inclui identificar posicionamentos em torno de questões que envolvam o religioso em cada formação disciplinar, as relações que se configuram no ambiente universitário e o contexto sociocultural ampliado em que nossos interlocutores se inserem.

O material que aqui apresentamos resulta da primeira etapa de projeto de pesquisa coordenado por Claudia Swatowiski. Como professora adjunta de Antropologia da UFU, Claudia ministra disciplinas em ambos os cursos. Dayane Rodrigues é estudante do curso de Psicologia, atualmente no oitavo período, e Otávio Alvarenga concluiu recentemente a graduação em Ciências Sociais. Ambos participaram do Programa de Iniciação Científica Fapemig / CNPQ e contribuíram para a primeira etapa deste projeto, que se estenderá por mais dois anos.

Em 2016, iniciamos a nossa pesquisa com a realização de um survey entre discentes dos cursos de Ciências Sociais e Psicologia com 16 perguntas diretamente relacionadas à questão religiosa. Alcançamos uma amostra significativa - 88 respondentes de Ciências Sociais e 100 de Psicologia, de um universo total de aproximadamente 150 e 400 estudantes regulares, respectivamente -, o que nos permite traçar o perfil religioso dos discentes de cada curso e compará-los, ainda que esse não seja nosso objetivo principal.

Paralelamente, realizamos entrevistas com estudantes de ambos os cursos, com o intuito de conhecer suas histórias de vida e perceber suas visões de mundo, especialmente no que diz respeito à relação entre a dimensão religiosa e o contexto universitário. Oito jovens de cada curso, com idades entre 19 e 22 anos e variação na declaração de pertencimento religioso, colaboraram para a composição de um material bastante diversificado.

Para além disso, através de observação participante e de conversas informais, procuramos perceber como os discentes (re)elaboram sua relação com a dimensão religiosa na interação com outros estudantes, com professores e com os conteúdos programáticos de cada curso. Sem dúvida, 
a participação de Dayane e Otávio como estudantes, circulando entre seus pares, compartilhando conversas nos corredores, nos espaços extramuros da universidade, nas redes sociais, foi fundamental para acessar e conhecer o universo pesquisado - ainda que eles estivessem diante do desafio de iniciar suas trajetórias como pesquisadores "observando o familiar" (VELHO, 1981).

O material obtido através de métodos quantitativos e qualitativos nos oferece pistas para compreender as relações que jovens estudantes estabelecem com a dimensão religiosa. Consideramos que estamos lidando com uma fase da vida particular - a juventude ${ }^{1}$-, em um contexto específico - o ensino superior em uma universidade pública do Triângulo Mineiro -, inserida em um contexto mais amplo de relações e visões de mundo - que tensiona religião, política e ciência. Isso implica, como veremos, considerar a forma como cada campo de saber enfrenta essa questão e, principalmente, as configurações e ambivalências produzidas no contexto de cada curso e das interações travadas ao longo da trajetória acadêmica desses estudantes.

Nossa pesquisa toma como referência a reflexão apresentada por Regina Novaes (1994) sobre religiosidade entre estudantes do curso de graduação em Ciências Sociais da Universidade Federal do Rio de Janeiro a partir de pesquisa realizada nos anos 90. A antropóloga chamou a atenção para o número de alunos que se declaravam "sem religião", assunto ao qual se dedicou posteriormente (NOVAES, 2006, 2013). Outros pesquisadores, inspirados pelo estudo de Novaes, voltaram a se debruçar sobre o universo dos estudantes de Ciências Sociais. No ano de 2000, uma equipe reunida pelo Núcleo de Estudos da Religião (NER) da Universidade Federal do Rio Grande do Sul (UFRGS) - com a colaboração da própria Regina Novaes - realizou pesquisa entre discentes de Ciências Sociais em diferentes instituições de ensino superior públicas e privadas do Brasil, compondo uma base de dados significativa (STEIL et al., 2001). Foram aplicados questionários com questões relativas à religiosidade e à política entre alunos das Universidades Federais de Minas Gerais, Juiz de Fora, do Rio de Janeiro e do Rio Grande do Sul, da Pontifícia Universidade Católica do Rio Grande do Sul e da UNISINOS, que renderam muitas reflexões (DEBATES

\footnotetext{
${ }^{1}$ Muito já foi discutido sobre a noção de juventude como construção sociocultural. Ver, por exemplo, Ariès (1981).
} 
DO NER, 2001). Posteriormente, Oro e Meirelles (2010) realizaram pesquisa comparativa sobre perfil religioso de jovens universitários brasileiros dos cursos de Ciências Sociais e de Medicina e teceram reflexões sobre a tensão entre religião e modernidade.

Em relação aos estudantes de Psicologia, tivemos maior dificuldade de encontrar material que se aproximasse de nossos interesses, pois as pesquisas que se debruçam sobre os universitários tendem ter preocupações e metodologias próprias dessa área de conhecimento. Assim, os trabalhos sobre o perfil de discentes de Psicologia que localizamos não nos permitiram estabelecer conexões diretas com os nossos dados e com nossas reflexões.

Passamos agora a contextualizar a nossa pesquisa, visando facilitar a interpretação dos dados que apresentaremos posteriormente.

\section{Contextualizando...}

A entrada na universidade geralmente representa para a/o estudante um mergulho em um novo mundo de relações e uma nova fase de suas vidas. ${ }^{2}$ Especialmente na grande área das Ciências Humanas, as reflexões geradas a partir do contato com novas teorias e conteúdos críticos podem gerar mudanças nas trajetórias individuais dos discentes bem como a revisão ou reelaboração de referenciais, valores e costumes herdados por "tradição" da família e do meio sociocultural de origem.

Ao mesmo tempo, é preciso considerar as experiências de vida que precedem o ingresso dos jovens na universidade. Questionamentos e/ou estranhamentos em relação às práticas sociais, moralidades e visões de mundo podem emergir antes da entrada na universidade (ainda que não estejam necessariamente formulados e explicitados), e, inclusive, ser esse um dos fatores que influenciam na opção por um curso na área de humanas.

Estamos, pois, diante de um universo predominantemente jovem, uma juventude universitária que projeta seu futuro diante de um momento de crise política e econômica e que convive com um acentuado "medo de sobrar" (NOVAES, 2007) - já que o estudo não garante emprego ou renda. Uma juventude muito inserida no universo das redes sociais, através

\footnotetext{
2 Para uma revisão bibliográfica da produção sobre juventude nas Ciências Sociais, ver Tavares e Camurça (2009).
} 
das quais se estabelecem rápidos e intensos fluxos de informações, (re) configuram-se identidades, compartilham-se sofrimentos e deflagram-se conflitos.

Essa juventude também se coloca em um cenário em que reivindicações por direitos de minorias ganham destaque nos debates públicos. As discussões sobre racismo, gênero e sexualidade estão na ordem do dia, nas campanhas da grande mídia, nos embates políticos, embora apenas pequena parte desses jovens esteja diretamente engajada em movimentos sociais e políticos organizados. Os movimentos feministas e de afirmação dos/das LGBTTs avançam em tensão com uma "onda" conservadora diretamente associada à "bancada evangélica"3. Em ambos os cursos sobre os quais nos debruçamos, tais temáticas estavam muito presentes como preocupação entre os estudantes, muitas vezes relacionadas a experiências pessoais, e também vinculadas a conteúdos disciplinares e a discussões sobre a atuação profissional, embora por vieses distintos.

Nesse contexto, nota-se, principalmente na Psicologia, uma forte presença da tensão entre ciência e religião, dentro de um registro moderno - na qual a ciência apresenta-se como produtora de "verdades", em contraponto às "crenças" da religião (LATOUR, 1994). Isso nos pareceu diretamente relacionado aos embates políticos enfrentados recentemente. É o caso das discussões em torno do projeto de lei - defendido por pastores evangélicos - que ficou conhecido como "cura gay", que permitiria que psicólogos realizassem tratamentos terapêuticos para "curar a homossexualidade", contrariando determinações do Conselho Federal de Psicologia.

Estávamos atentos, portanto, aos impactos da formação em cada curso pesquisado, assim como o ethos predominante em cada um desses contextos. No curso de Psicologia da UFU, observamos uma preocupação em afirmar a área como ciência, aproximando-a da biomedicina. É muito associada a uma preocupação com a personalidade e os sofrimentos humanos. Ao mesmo tempo, configura-se como lócus privilegiado de uma aproximação de uma representação individualizada e individualizante de interioridade psicológica, predominante nas classes mais favorecidas de nossa sociedade

\footnotetext{
${ }^{3}$ Para uma discussão sobre a relação entre religião e política no Brasil contemporâneo, ver Freston (2006), Burity e Machado (2005, 2014), Oro (2003), Machado (2006), Vital e Lopes (2013), Vital, Lopes e Lui (2017) e Almeida (2017).
} 
(VELHO, 1981; DUARTE, 2003). No curso de Ciências Sociais, marcado por discussões críticas sobre sistema socioeconômico e político, delineia-se um ethos secularizado associado a um posicionamento político de esquerda. Embora conte com a Antropologia, geralmente são a Sociologia e a Ciência Política que despertam maior interesse nos estudantes na UFU.

Feitas essas considerações iniciais, partamos para a análise dos dados e discussão do material obtido em nossa pesquisa.

\section{Perfil religioso dos estudantes}

Comecemos por uma apresentação geral de nossa amostra. O universo dos respondentes do curso de Ciências Sociais é composto por maioria feminina (71,6\%). 85,2\% dos estudantes têm entre 17 e 24 anos. 60,2\% cursaram o Ensino Médio em Uberlândia; o restante, o fez em outras cidades do Triângulo Mineiro, interior de São Paulo ou Goiás. 71,6\% dos respondentes disseram que não trabalham ${ }^{4}$. Alguns dos que indicaram que trabalham são bolsistas de programas da própria universidade (PET, PIBID, PIBIC). O curso é matutino, com entrada anual, e as aulas acontecem no campus Santa Mônica, no mesmo bloco da História, da Geografia e da Filosofia.

Encontramos variações no universo dos estudantes do curso de Psicologia: maior presença feminina (82\%); 87\% têm entre 17 e 24 anos; $66 \%$ cursaram Ensino Médio em Uberlândia; 80\% não trabalham. O curso é integral, tem entrada semestral e está sediado no campus Umuarama, juntamente com os cursos da área da saúde.

Em resumo, podemos dizer que, em ambos os cursos, predominam discentes do sexo feminino, dedicadas exclusivamente ao estudo, residentes em Uberlândia, ainda que grande parte dos alunos venham de outras cidades da região para estudar na UFU. Acrescentamos que, em ambos os cursos, predomina uma amostra de estudantes cursando os primeiros anos da graduação.

Em relação à religiosidade, entre os entrevistados das Ciências Sociais

\footnotetext{
${ }^{4}$ Esse dado é bastante relevante para a compreensão do perfil religioso dos estudantes. Como mostrou a pesquisa coordenada pelo Núcleo de Estudos da Religião (STEIL et al., 2001), há uma diferença considerável no perfil de estudantes de cursos matutinos e cursos noturnos de Ciências Sociais em universidades públicas. Na UFU, não há curso de Ciências Sociais noturno.
} 
temos um grande número de autodeclarados sem vínculos religiosos: $48,86 \%$ sem nenhuma religião; $4,55 \%$ ateus; $7,95 \%$ agnósticos, somando $61,36 \%$. Dentre os que declararam filiação religiosa, temos: 11,36\% católicos, 9,09\% espíritas, 7,95\% evangélicos, 1,13\% candomblecistas, 2,27\% budistas, 3,40\% umbandistas, e 1,13\% Fraternidade Branca. Chama a atenção, portanto, neste universo a maioria absoluta de pessoas que negam uma identidade religiosa.

Entre os estudantes de Psicologia, o quadro apresenta diferenças: $37 \%$ sem religião, $4 \%$ ateus, $5 \%$ agnósticos, somando $46 \%$. Dentre os que declararam filiação religiosa temos: $22 \%$ católicos, $17 \%$ espíritas, $8 \%$ evangélicos, $3 \%$ umbandistas, $2 \%$ budistas, $1 \%$ candomblecista, $1 \%$ wicca, $1 \%$ cristão (indeterminado). Ou seja, entre os estudantes de Psicologia, temos um número maior de estudantes que declaram algum tipo de pertencimento religioso, com destaque para católicos e espíritas.

Importante dimensionar esses números em relação ao perfil religioso de jovens brasileiros, na mesma faixa etária. Considerando dados do censo 2010, na população com idade entre 18 e 24 anos, temos 63,83\% de católicos, 21,11\% de evangélicos, 1,53\% de espírita, 0,29\% de candomblecista/ umbandista e 10,50\% sem religião (incluindo ateus e agnósticos). A diferença nos percentuais entre a média brasileira e os estudantes pesquisados é muito grande em ambos os cursos, principalmente o grupo dos sem religião, que exploraremos mais adiante. Chama a atenção também o maior número de espíritas em relação à média nacional, principalmente no caso dos discentes de Psicologia. Indicaremos alguns aspectos que podem nos ajudar a compreender esses números (Gráfico 1). 


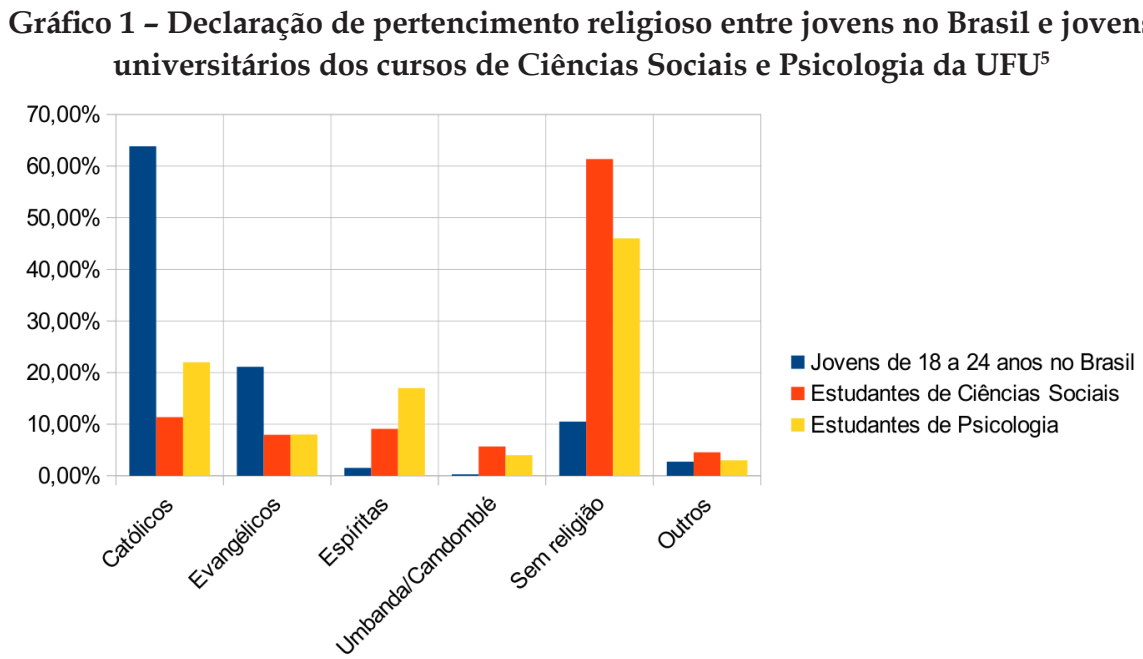

Fonte: Elaborado pelos autores.

\section{Espiritas}

Primeiramente, é preciso considerar relação entre religiosidade, escolaridade e renda, o que significa apontar para o acesso restrito ao ensino superior no Brasil - e especialmente às universidades públicas brasileiras. Na UFU, ainda que a política de cotas garanta um corpo discente minimamente heterogêneo, predominam brancos de camadas médias $^{6}$, aspecto que tende a se acentuar nos cursos diurnos, e impacta no perfil religioso desse universo. Dados do censo indicam que o espiritismo kardecista é a religião que mais concentra pessoas com maior escolaridade e maior renda.

Também é importante registrar a forte influência do espiritismo no Triângulo Mineiro - muito em função do trabalho realizado por Chico Xavier a partir de Uberaba, cidade próxima à Uberlândia ${ }^{7}$. No último censo, $7,42 \%$ da população de Uberlândia se declarou espírita, número

\footnotetext{
${ }^{5}$ Gráfico elaborado pelos autores a partir de dados do Censo 2010 e do survey realizado na Universidade Federal de Uberlândia em 2016.

${ }^{6}$ Conforme demonstrou pesquisa sobre o perfil dos estudantes da UFU realizada em 2014, $60 \%$ dos alunos se autodeclararam brancos e 56,5\% cursaram o Ensino Médio em escola pública. A renda familiar per capita dos estudantes dos campi de Uberlândia foi calculada em $\mathrm{R} \$ 1.021,50$.

${ }^{7}$ Para uma análise da importância de Chico Xavier na história do espiritismo kardecista brasileiro, ver Lewgoy (2001b).
} 
bastante acima da média de espíritas na população brasileira, que é de $2 \%$, e ainda assim abaixo dos percentuais encontrados entre os estudantes que responderam à nossa pesquisa.

Dentre os alunos da Psicologia da UFU, encontramos muitas declarações de interesse e simpatia pelo espiritismo, mesmo entre aqueles que não declaram nenhum pertencimento religioso. Entende-se que há um contexto de boas relações estabelecidas por estudantes espíritas com os demais estudantes e que esses se sentem à vontade para assumir sua identidade religiosa de forma mais aberta. Soma-se a isso o fato de estudantes de Psicologia - muitos deles espíritas - terem se reunido e criado a Liga Acadêmica de Psicologia e Espiritualidade, que tem como proposta aprofundar estudos em torno da questão religiosa.

Conversamos com um estudante que teve seu primeiro contato com o espiritismo através de seus colegas da UFU. Rafael ${ }^{8}, 21$ anos, conta que se distanciou do catolicismo e passou a admirar colegas espíritas na universidade. "São pessoas tão do bem, sabe?! (...) eu percebi que eles levam a vida tão bem, e fazem tão bem às outras pessoas", disse ele valorizando uma certa ética do cuidado, presente tanto na Psicologia, quanto no espiritismo.

Além disso, o espiritismo é uma religiosidade que se alinha a um projeto de laicidade, valoriza o saber letrado como signo de distinção e busca se aproximar de raciocínios científicos (LEWGOY, 2000, 2001a), aspectos que favorecem a aproximação com o universo acadêmico. Também carrega uma "filosofia evolucionista, liberal e individualista em seu bojo" (LEWGOY, 2001a, p. 111), o que cria uma distância em relação à perspectiva crítica das Ciências Sociais.

\section{Evangélicos}

Se o número de espíritas é relativamente alto entre os estudantes de ambos os cursos, o mesmo não ocorre em relação aos evangélicos. Observa-se que o número de pessoas que se declaram evangélicas em ambos os cursos está bastante abaixo da média nacional para a faixa etária e também da

\footnotetext{
${ }^{8}$ Todos os nomes de estudantes entrevistados citados ao longo deste artigo são fictícios.
} 
expressiva presença no Triângulo Mineiro. A cidade de Uberlândia concentra 25,6\% de evangélicos, número acima da média nacional, que é de $22,2 \%$, sendo que $14,27 \%$ da população é pentecostal e 7,76\% são evangélicos não determinados.

A partir de dados do Censo, também sabemos que os pentecostais estão mais concentrados nas camadas de menor renda e menor escolaridade. Por isso, não nos surpreende que estejam pouco presentes entre os universitários. Ademais, boa parte dos estudantes que se declararam evangélicos em nossa pesquisa indicou frequentar regularmente igrejas protestantes históricas, que possuem uma forte marca de racionalização e valorização do estudo. Alguns discentes identificaram-se apenas como protestantes, outros acrescentaram informação sobre a igreja que frequentam. Na Psicologia, foram mencionadas a Igreja do Evangelho Quadrangular e Presbiteriana. Entre os estudantes de Ciências Sociais, Assembleia de Deus, Adventista do Sétimo Dia, Sara Nossa Terra, Igreja Presbiteriana Renovada e Metodista foram citadas.

Dentre as identidades religiosas do universo pesquisado, provavelmente são os evangélicos pentecostais que carregam a marca de maior desvantagem social no contexto pesquisado, frequentemente associados ao conservadorismo e à ostensiva arrecadação de dinheiro. Nesse contexto, conversamos com Fabrícia, 20 anos, criada dentro da Assembleia de Deus. Ela manteve sua filiação religiosa após entrar nas Ciências Sociais e costuma ir à igreja duas vezes por semana. Tímida, prefere manter discrição em relação a sua identidade religiosa. Não participa das festas organizadas pelos estudantes, nem de movimentos sociais, mantendo-se um pouco distante das redes de sociabilidade dos colegas do curso. Também enfrenta alguns conflitos entre discussões travadas nas disciplinas e suas referências religiosas, mas procura separar os dois universos para lidar melhor com eles. E tem obtido êxito. É uma das estudantes com maior rendimento na turma.

Entrevistamos também Carlos, estudante de Ciências Sociais que frequentou a Igreja Batista Renovada durante 17 anos de sua vida. Já como estudante de Ciências Sociais, sua igreja aderiu à teologia da prosperidade. Carlos passou a questioná-la, identificando uma "mercantilização da lógica cristã". Segundo ele, o cotidiano de debates no curso ajudou no processo de releitura de sua fé. Carlos não passou a questionar a existência de Deus, mas desvinculou-se da igreja que frequentava, levando o restante da família consigo. A partir de uma leitura política da Bíblia, decidiu filiar-se 
ao PCdoB. Hoje em dia, Carlos se enquadraria no que foi classificado no último censo como "evangélico não determinado".

É interessante perceber que, para além dos conflitos e tensões que surgem ao longo da formação acadêmica, eventos de superação - como conseguir uma vaga na universidade pública - podem ser motivo de fortalecimento da fé. É o caso de Patrícia, 19 anos, estudante de Psicologia, evangélica. Ela saiu de uma pequena cidade do Triângulo Mineiro para estudar em Uberlândia. Por isso, atualmente frequenta a Igreja Presbiteriana apenas quando volta para a sua cidade de origem. Ainda assim, acredita que entrar na universidade a tenha feito viver sua fé de maneira mais forte. Patrícia conta que orou muito para conseguir entrar no curso e atribui a conquista à sua religiosidade. Considerando a acirrada disputa por vagas em universidades públicas brasileiras, o ingresso em um curso do ensino superior em uma universidade federal pode ser um evento muito marcante na trajetória de estudantes que vêm de um contexto socioeconômico desfavorável.

\section{Católicos}

Em relação aos católicos, chama a atenção que o Triângulo Mineiro foge a perfil médio do Estado. Em Uberlândia, $54,7 \%$ da população declarou-se católica no censo de 2010, em um Estado com 70,4\% de população católica, sendo que a média nacional é de $64,6 \%$. Ainda assim, são maioria e se fazem bastante visíveis na região, principalmente através de celebrações, festividades e peregrinações.

Entre os estudantes católicos, encontramos relatos de abalos de sua fé após o ingresso na universidade, mesmo que isso não tenha sido suficiente para uma mudança de identidade religiosa. Clarice, formanda no curso de Ciências Sociais, é exemplo de uma trajetória de permanência e ressignificação de sua religiosidade católica no percorrer da graduação. Natural de Uberaba, vem de uma família católica praticante. Na adolescência, envolveu-se com a Renovação Carismática Católica (RCC) contra a vontade da família e tornou-se líder de um grupo de jovens. Mudouse para Uberlândia aos 18 anos para cursar Ciências Sociais. Ao longo da faculdade começou a enxergar algumas contradições dentro do movimento e afastou-se completamente do grupo. Hoje em dia mantém sérias críticas à Igreja Católica como instituição, mas mantém sua fé e frequenta missas regularmente. 
Na Psicologia, conversamos com Marina, 19 anos. Também autodeclarada católica, frequenta a igreja duas ou três vezes por semana. Na universidade, participa do Grupo de Orações Universitário (GOU), da Renovação Carismática Católica. Marina aponta que ingressar na universidade fortaleceu suas crenças, pois na UFU encontrou pessoas que compartilhavam das mesmas ideias que ela. Marina pensa que, se não tivesse começado a frequentar o GOU, talvez a sua situação hoje fosse outra. Nesse caso, o ambiente universitário, em sua diversidade, fortaleceu o vínculo religioso institucional da estudante.

Registramos também, no curso de Ciências Sociais, casos de católicos gays que causam confusão aos colegas que não compreendem como se mantêm vinculados a uma instituição religiosa que não consente com as relações homoafetivas. Em geral, foram criados em famílias católicas e permanecem dentro do registro de religiosidade católica, independentemente da orientação sexual. Se a fé desses estudantes sobrevive aos dogmas da igreja, eles têm de convier com um duplo estranhamento - no contexto religioso e entre os colegas de curso.

\section{Religiões de matriz africana}

Passemos a abordar os autodeclarados umbandistas e candomblecistas. Destacamos casos de adesão às religiões de matriz africana após ingresso no ensino superior. É o que aconteceu com Rebeca, 23 anos, estudante de Psicologia e praticante de umbanda. Ela nasceu em Paracatu (MG), cidade onde morava com seus pais até se mudar para Uberlândia, para fazer faculdade. Ingressou no curso de Psicologia em 2014. De família católica, Rebeca conta que ficou algum tempo sem praticar nenhuma religião, questionando todas as suas crenças. Em 2016 começou a buscar outras religiões e se interessou pela umbanda. "Foi assim, sempre gostei de espiritismo, sempre gostei de umbanda, só que minha família não gostava porque eles são católicos e têm preconceito. E aí eu vim pra cá e fui entrando em contato com pessoas que frequentavam a umbanda, fui lendo sobre a umbanda e aí num belo dia eu fui, por iniciativa minha, mas me indicaram um centro. Um amigo meu falou: 'Ah, é bom, é legal' e eu fui."

Flávio, 21 anos, natural de Uberlândia, estudante do 3o ano do curso de Ciências Sociais tem uma trajetória semelhante. Ele nasceu em uma família católica, fez catequese e crisma. Entre os 15, 16 anos, se distanciou da Igreja Católica por desconforto com a heteronormatividade defendida 
na igreja. Quando iniciou a graduação, considerava-se agnóstico. Depois, através de um professor, se aproximou do candomblé e passou pelos ritos de iniciação. Também elegeu o candomblé como tema de pesquisa na área de Antropologia, somando-se aos inúmeros casos de antropólogos que se convertem ao candomblé.

Ainda que haja poucas pessoas que se declarem umbandistas e candomblecistas, os cursos de Humanas tendem a valorizar as religiões de matriz africana. Em um contexto de combate ao racismo, as religiões de matriz africana - especialmente o candomblé - são associadas a ações afirmativas, e apoiá-las significa uma defesa política de uma cultura de negros. Além disso, as religiões afro-brasileiras são consideradas espaços de tolerância da diversidade sexual e de gênero. Nesse contexto, muitos estudantes tendem a se aproximar das religiões de matriz africana, ainda que seja uma aproximação pontual, sem intenção de conversão.

\section{Sem religião}

O grupo dos sem religião merece maior atenção, especialmente no caso dos estudantes de Ciências Sociais, que compõem parcela mais significativa do total de respondentes. Sabe-se, a partir do Censo, que o número de pessoas que se declaram sem religião no Brasil tem crescido significativamente nas últimas décadas, chegando a $8 \%$ da população em 2010. Em uma análise dos dados do Censo de 2010, Regina Novaes (2013) destaca que boa parte daqueles que se declaram sem religião são jovens, do sexo masculino, vivendo principalmente nas cidades, com boa representação na região Sudeste. Entre a população de jovens de 20 a 24 anos, 10,03\% declaramse sem vínculo religioso. Mesmo assim, em nosso universo de pesquisa, a declaração de não pertencimento religioso é acentuadamente maior: 61,36\% nas Ciências Sociais e $46 \%$ na Psicologia.

É necessário considerar que não se trata necessariamente da adoção de uma posição antirreligiosa ou antiteísta. Sabe-se que muitas vezes se declarar sem religião não significa não ter nenhum tipo de prática, interesse ou crença religiosa. Pode sinalizar a negação de uma filiação institucional ou a adesão a práticas não identificadas propriamente como religiosas. Nesse sentido, Novaes (2013) identifica uma redefinição de vínculos ou pertencimentos, que passam a se firmar de outros modos, e nem sempre "por dentro de circuitos institucionais, mas também fora e à margem". Ela alerta que é problemático fazer generalizações em relação àqueles que se 
declaram sem religião, já que, se por um lado sabemos que desse grupo uma parcela muito pequena é de ateus ou agnósticos, para muitos desses jovens as instituições religiosas não perderam o seu valor de lócus de agregação, motivação ou afirmação de sentido. Assim, aqueles que se declaram sem religião podem estar produzindo sínteses pessoais ao combinar elementos de diferentes tradições religiosas e esotéricas.

Tendo como base pesquisas realizadas anteriormente com estudantes de Ciências Sociais (NOVAES, 1994, STEIL et al.., 2001 ORO; MEIRELLES, 2010), já esperávamos um alto percentual de autodeclarados sem religião. Por isso, incluímos algumas perguntas que visavam compreender melhor esse universo. As respostas, de fato, nos ajudam a pensar a questão e compreender diferenças no perfil dos estudantes de ambos os cursos. $\mathrm{Na}$ Tabela 1 podemos visualizar uma síntese desses dados.

Tabela 1 - Perfil dos sem religião, incluindo agnósticos e ateus ${ }^{9}$

\begin{tabular}{|c|c|c|}
\hline & Ciências Sociais & Psicologia \\
\hline Frequentam espaços religiosos & $18,50 \%$ & $6,52 \%$ \\
\hline Práticas Nova Era & $24,07 \%$ & $19,56 \%$ \\
\hline $\begin{array}{c}\text { Interesse em alguma religião, filosofia ou } \\
\text { conhecimento espiritual }\end{array}$ & $61,11 \%$ & $50,00 \%$ \\
\hline Já tiveram religião & $69,64 \%$ & $87,23 \%$ \\
\hline Deixaram religião após entrar no curso & $17,85 \%$ & $46,80 \%$ \\
\hline $\begin{array}{c}\text { Acreditam em Deus, em um ser superior ou } \\
\text { metafísico }\end{array}$ & $41,07 \%$ & $57,44 \%$ \\
\hline
\end{tabular}

Fonte: Elaborada pelos autores.

Após a pergunta direta sobre pertencimento religioso, indagamos aos estudantes se frequentavam algum espaço religioso. Dentre os sem religião, incluindo ateus e agnósticos, alguns indicaram frequentar espaços religiosos, sendo muito maior o número de respostas entre os estudantes de Ciências Socais. Os espaços mais citados foram os centros espíritas e espaços de cultos afro-brasileiros (umbanda e candomblé), mas também foram mencionados uma igreja católica e um centro xamânico.

\footnotetext{
${ }^{9}$ Tabela elaborada pelos autores a partir de resultados do survey realizado em 2016.
} 
Depois perguntamos se realizavam algum tipo de prática religiosa ou de autoconhecimento. Entre os estudantes de Ciências Sociais predominam as práticas que costumamos chamar de Nova Era (meditação, reiki, xamanismo, tarô, regressão, etc.) e entre os estudantes de Psicologia esse tipo de prática está mesclada com menções recorrentes de orações e rezas. O que chama a atenção aqui também é que os estudantes de Ciências Sociais estejam mais afeitos a esse universo do que os de Psicologia. O que podemos entender é que as práticas Nova Era, também associadas a uma "nebulosa místicoesotérica" (CHAMPION, 2001), permitem aos estudantes escapar da crítica que enfatiza relações de poder e autoridade das instituições religiosas e encontrar liberdade para criar seus próprios arranjos de técnicas e práticas sem compromisso ${ }^{10}$.

Outra pergunta que fizemos visando obter mais informações sobre os discentes que não declararam filiação religiosa foi: "Você tem interesse em alguma religião, filosofia ou conhecimento espiritual?". Para ela, obtivemos um alto percentual de respostas positivas, com destaque para os estudantes de Ciências Sociais $(61,11 \%)$. Estudantes de ambos os cursos mencionavam, principalmente, meditação, budismo, candomblé e xamanismo. Estudantes de Ciências Sociais apontaram com maior frequência religiões orientais, e estudantes de Psicologia, o espiritismo e a umbanda. Essas respostas reforçam o indicativo de maior aproximação dos alunos de Ciências Sociais ao universo Nova Era.

Outro dado relevante em relação a esse grupo de estudantes é relativo à condição pregressa. Nas Ciências Sociais, 69,64\% dos sem religião disseram que já tiveram alguma religião, e apenas $25 \%$ disseram ter deixado sua religião após ingresso no curso, ou seja, que isto ocorreu antes do ingresso na universidade. Na Psicologia, 87,23\% disseram que tinham religião, sendo que quase metade desses deixaram a religião após entrar no curso. Esses dados nos levam a entender que nas Ciências Sociais temos um perfil de ingressantes mais secularizados que na Psicologia, enquanto entre os ingressantes de Psicologia temos mais religiosos que se desvinculam de uma identidade religiosa ao longo do curso. Nesse contexto, observamos

${ }^{10}$ Em um quadro mais amplo, destacamos o estudo comparativo internacional entre universitários - que no Brasil contou com a colaboração de Deis Siqueira - enfatizando uma forte tendência de busca por "religiosidades não convencionais" (VALLE-HOLLINGER, 2002). 
o movimento de "desinstitucionalização" religiosa (HERVIEU-LEGER, 2008), afetando principalmente as identidades cristãs.

Somamos ainda mais um dado. Fizemos a seguinte pergunta: "Você acredita em Deus, um ser superior ou metafísico?". Dos estudantes de Ciências Sociais sem religião, excluindo agora os ateus e agnósticos, $53,50 \%$ responderam positivamente à pergunta. Já entre os estudantes de Psicologia, havia mais adesão a uma concepção de entidade metafísica $64,86 \%$ responderam sim -, somados aos indicativos de realização de rezas e orações, reforçam a ideia de uma religiosidade não institucionalizada, vivida na forma de crenças e práticas individual e privada.

Importante também estabelecer uma relação desse quadro com dados sobre a religiosidade dos pais desses estudantes. Se levarmos em consideração a filiação de autodeclarados sem religião, ateus e agnósticos, temos o seguinte perfil (Gráfico 2):

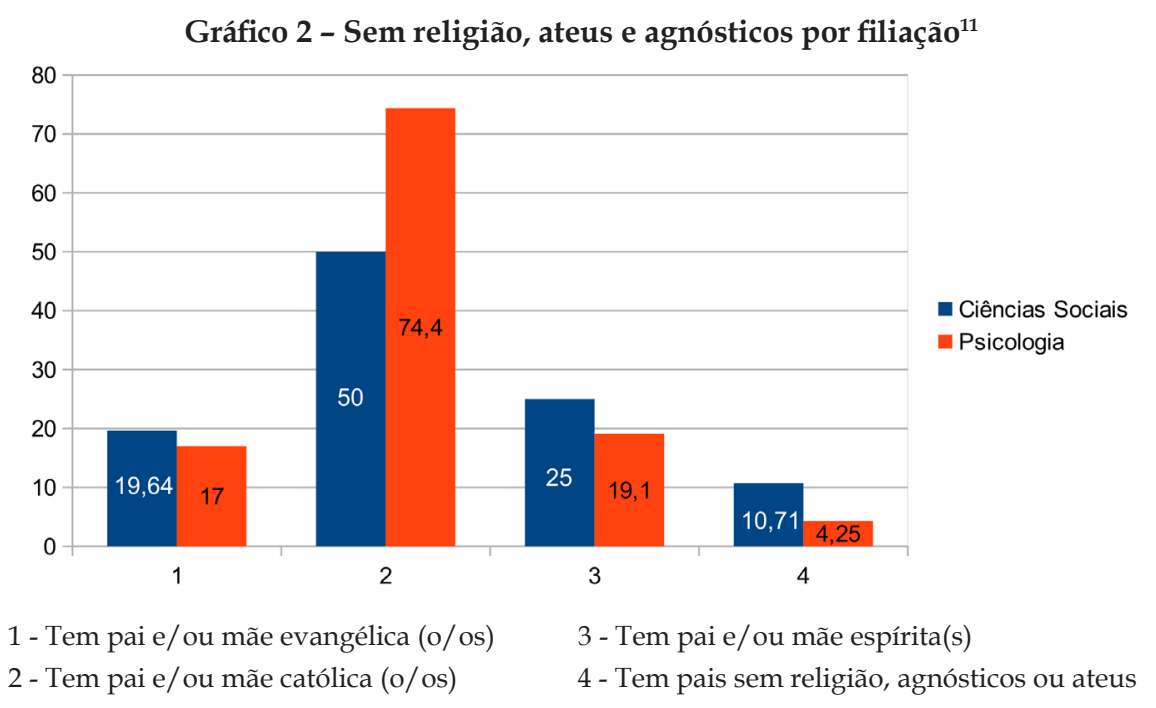

Fonte: Elaborado pelos autores.

Desse gráfico, por um lado, chamamos a atenção para o alto percentual de estudantes de Psicologia com pai ou mãe católico. Por outro, os estudantes de Ciências Sociais indicam ter pais sem vínculos religiosos com

\footnotetext{
${ }^{11}$ Gráfico elaborado pelos autores a partir de resultados do survey realizado em 2016.
} 
mais frequência que os estudantes de Psicologia. Também é relativamente alto o número de pais ou mães espíritas entre estudantes sem declaração de vínculo religioso, principalmente os estudantes de Ciências Sociais. Tais aspectos podem estar associados a classe social, escolaridade e perfil da população regional, como apontamos anteriormente. Em relação a filhos de evangélicos, embora em menor percentual, temos um número considerável de filiações. Em conversas informais, ouvimos alguns relatos de conflitos entre estudantes sem religião e pais pentecostais, muito marcados pelo indicativo de uma ruptura radical e postura bastante crítica em relação à religião dos pais.

Diante desses dados, podemos notar tendências diferentes entre os universos dos estudantes das Ciências Sociais e da Psicologia. Nas Ciências Sociais, temos mais estudantes que se declaram sem religião antes de entrar no curso e mais afeitos às práticas Nova Era. Na Psicologia, temos maior número de estudantes que se desvinculam de uma identidade religiosa após entrar no curso, na sua maioria, oriundos de famílias cristãs, e permanecem com algum tipo de crença ou prática conectada a essas origens. A m b o s os casos apontam para a vivência da religiosidade de maneira mais afeita a uma ideologia individualista - valorizando a autonomia e a liberdade dos sujeitos para construírem suas próprias trajetórias e sua relação com o religioso.

\section{Intolerância religiosa}

Incluímos em nosso questionário uma pergunta sobre intolerância religiosa. Ao serem indagados se presenciaram alguma situação de intolerância dentro de sala de aula, 51\% dos discentes de Ciências Sociais indicaram já terem observado algo dessa natureza, seja por parte de estudantes $(81 \%$ dos casos), seja vindo de professores (50\%). Entre os alunos de Psicologia, 60\% disseram ter presenciado situações de intolerância. Destes, 90\% observaram situações envolvendo discentes, e 75,9\% envolvendo docentes. Diante desses números, nos interessava saber o que esses estudantes entendiam como intolerância religiosa e quais as situações em que isso teria ocorrido.

No questionário, havia um espaço livre para comentários imediatamente após a pergunta sobre intolerância religiosa. Alguns respondentes escreveram algumas linhas sobre o assunto. Mas foi principalmente nas entrevistas e conversas informais que conseguimos entender melhor esse quadro. Mapeamos situações recorrentes, embora saibamos que elas 
não esgotam o leque de possibilidades do que viriam a ser os casos de intolerância religiosa.

No contexto mais amplo de discussões em torno da intolerância religiosa no Brasil, temos muitos registros de manifestação violenta contra espaços de culto e praticantes de religiões de matriz africana (SILVA, 2007). Isso decorre, principalmente, da disseminação de leituras cosmológicas agonísticas compartilhadas por denominações neopentecostais, dentro das quais entidades da umbanda e do candomblé são identificadas como espíritos demoníacos.

No entanto, casos de intolerância religiosa contra religiões de matriz africana não foram registrados pelos estudantes que participaram de nossa pesquisa - nem nos questionários, nem em entrevistas, nem em conversas informais. O que eles reportavam era um contexto de valorização das identidades associadas a religiões afro-brasileiras capaz de constranger manifestações de intolerância dentro de sala de aula ou nas relações entre os estudantes do curso. Especialmente no contexto das Ciências Sociais, tendese a valorizar as religiões de matriz africanas, pois se trata de reconhecer que há produção de um lugar marginal historicamente construído para as religiosidades de matriz africana, que se soma ao contexto intolerância religiosa vivido no Brasil contemporâneo.

Então, a que se referiam os estudantes como intolerância religiosa? Obtivemos relatos, em ambos os cursos, mas principalmente nas Ciências Sociais, de estigmatização de grupos evangélicos a partir de um debate político que tende a produzir uma leitura homogeneizante e estereotipada desse grande grupo religioso a partir dos posicionamentos da "bancada evangélica". Nos enfrentamentos político-morais, são "os evangélicos" - como categoria genérica - que vão ocupar o lugar do conservador e do intolerante, e por isso, receber críticas diretas.

Carlos, entrevistado das Ciências Sociais, de família evangélica, já referido anteriormente, comentou que o estereótipo do "crente" reproduzido no curso o incomoda, e observa uma abordagem sempre negativa em torno do cristianismo. Outra estudante de Ciências Sociais, que se identificou como protestante, registrou: "Na verdade, não é uma intolerância, mas é uma certa tendência a ridicularizar quem faz parte de alguma religião protestante".

Comentários semelhantes foram feitos por estudantes da Psicologia. "A intolerância religiosa que presenciei foram algumas 'piadinhas' que alguns alunos e professores fizeram sobre determinada religião", escreveu 
uma aluna espírita. "A Psicologia é um curso que exalta a liberdade do indivíduo em vários aspectos, mas, na prática, muitos alunos e professores são intolerantes ao cristianismo, não por de fato o conhecerem, mas por reproduzir um discurso do que aparece na mídia. Não medem palavras para criticar dentro de sala de aula, sendo que muitas vezes o discurso é ofensivo a quem pratica tal religião", declarou outra estudante, que se identificou como evangélica protestante.

Dayane lembra-se de um dia em que encontrou, nos corredores do bloco da Psicologia, estudantes que diziam estar profundamente incomodados com os comentários feitos por um/a professor/a sobre a crença em Deus em tom de piada em uma aula sobre psicanálise freudiana. Se nos escritos de Freud (1997) a questão religiosa assume um lugar de compensação pelo sentimento de desamparo, oferecendo uma explicação psicológica para a crença religiosa, e a questão da sexualidade, disciplinada pela moralidade repressora, frequentemente associada à religião, ganha centralidade, o que parece ter gerado mais desconforto entre os estudantes foi a forma como o/a docente abordou a questão, tornando a situação em si alvo de comentários.

Nesse contexto, percebe-se que os estudantes, ao apontarem a presença de intolerância religiosa, referem-se a contextos de atitudes críticas consideradas generalizantes ou desrespeitosas em relação àqueles que têm religiosidade ou às religiões cristãs. Na perspectiva desses estudantes, a forma como a questão religiosa ou determinadas identidades religiosas por vezes são tratadas caracterizariam uma intolerância religiosa.

É preciso então situar as inúmeras indicações de intolerância religiosa que, em ambos os cursos, ultrapassam o percentual de declaração de pertencimento religioso. Considerar a alta frequência de respostas positivas para a pergunta sobre intolerância religiosa implica reparar que as observações não se restringem àqueles que se identificaram como religiosos. Ou seja, o universo dos que responderam positivamente para intolerância religiosa é composto por estudantes com declaração religiosa variada (católicos, evangélicos, espíritas, candomblecistas, umbandistas) e inclui agnósticos e sem religião.

Por um lado, já sabemos que os sem religião não são, necessariamente, pessoas que se distanciaram de práticas religiosas/espirituais. Mesmo sem declarar pertencimento religioso, muitos estudantes mantêm algum tipo de prática ou interesse religioso, o que pode implicar uma sensibilidade para com o tema. São esses mesmos estudantes que, por vezes, sinalizam que as críticas à adesão religiosa ou a determinadas religiões podem ser percebidas 
como impertinentes. "No curso de Ciências Sociais percebo constantemente preconceitos e deboches com relação às religiões evangélicas e católicas", escreveu uma estudante de Ciências Sociais, 24 anos, autodeclarada sem religião.

Estudantes que responderam "não" para a pergunta sobre intolerância religiosa também se manifestaram: "os professores fazem algumas críticas de forma moderada sobre o tema relacionando com as teorias que expõem e, para os mais fanáticos, a contradição entre a teoria exposta e a prática religiosa soa como 'desrespeito' ou 'intolerância'. No entanto, não acredito que essa prática aconteça na instituição, sinto que, a maior parte do tempo, os alunos se colocam como hostilizados após tentar forçar em sala a crença religiosa como verdade em detrimento da teoria explanada em sala", escreveu uma estudante de Psicologia que se declarou sem religião, de família católica. Outra estudante de Psicologia, também autodeclarada sem religião, ex-espírita, se manifestou: "sempre a religião irá entrar em conflito com temas da Psicologia. E que bom que não dão certo mesmo, além disso se religião fosse isso tudo não precisava de psicologia. Essas crenças religiosas tradicionais fazem mal para a sociedade e para as pessoas"12.

Estamos diante, portanto, de um contexto em que parte dos estudantes (e também docentes) tende a explicitar posicionamentos críticos relativos às religiões, muitas vezes associados a perspectivas teóricas críticas, e parte tende a não aprovar o que seria uma postura antirreligiosa. Parafraseando Geertz (2001), poderíamos chamá-los de "anti-antirreligiosos".

Uma outra situação ilustra bem a presença desse embate entre estudantes de Psicologia. Em grupo de uma rede social, alunos de Psicologia discutiam a respeito de uma postagem de um graduando do curso, católico, em seu blog sobre assuntos religiosos. A publicação falava a respeito da submissão da mulher bíblica diante do homem sob uma perspectiva cristã. Através de uma argumentação intelectualista, o estudante defendia que não se tratava de uma relação de opressão. Várias pessoas se sentiram ofendidas com o que leram no blog e se posicionaram contra o pensamento do autor do texto. "Eu fico pensando no tipo de profissionais que a Psicologia está formando!", escreveu um estudante em uma mensagem enviado para o

${ }^{12}$ Destacaríamos aqui a expressão "faz mal" como um indicativo de avaliação da adesão religiosa por seus impactos psíquicos. 
grupo. De outro lado, algumas pessoas concordavam e apoiavam a linha de raciocínio da publicação no blog e procuravam responder às críticas que lhe foram feitas. Outros estudantes se posicionaram de uma terceira forma. Discordavam do "ataque" que estava sendo feito ao aluno e defendiam a ideia de que seria preciso primeiro entender que ele estava em um espaço fora da universidade e que a publicação seguia um conjunto de crenças compartilhadas no contexto religioso em que estava inserido durante toda a sua vida. Defendiam ainda que a publicação não estava obrigando ninguém a concordar com as ideias expostas e, portanto, as pessoas precisavam agir com mais respeito. Nesse terceiro grupo, portanto, podemos entender melhor o posicionamento daqueles que chamamos "anti-antirreligiosos".

Sendo assim, poderíamos dizer que a intolerância religiosa, no contexto pesquisado, é entendida como uma atitude crítica considerada desrespeitosa diante de um universo heterogêneo e, em boa parte, sensível à questão religiosa. A exigência que se coloca é de uma postura não hierarquizante e não homogeneizante por parte de estudantes e docentes perante a questão religiosa.

\section{Considerações finais}

Ao conhecer o perfil religioso dos estudantes de Ciências Sociais e Psicologia da Universidade Federal de Uberlândia, deparamo-nos com um universo - majoritariamente feminino - interessante para pensar. $\mathrm{O}$ material que conseguimos reunir nessa primeira etapa de pesquisa nos permite realizar algumas reflexões. Pudemos perceber as diferenças no perfil dos ingressantes dos Cursos de Ciências Sociais - mais secular e Psicologia - mais religioso - e o impacto do meio acadêmico sobre as declarações de filiação religiosa, especialmente entre os estudantes de Psicologia. Nas Ciências Sociais encontramos um universo maior de jovens que declaram ter ingressado no curso sem vínculo religioso, fazendo-nos entender que há uma afinidade, anterior ao ingresso na universidade, entre o perfil desses estudantes e a proposta dessa área de conhecimento. $\mathrm{Na}$ Psicologia, encontramos maior persistência de identidades institucionais definidas e também maior número de pessoas que ingressaram com vínculo religioso e deixaram de declará-lo após o ingresso na universidade, ainda que mantivessem suas crenças - sinalizando uma privatização da experiência religiosa. Nesse contexto, os estudantes de Psicologia tendem a manter-se mais próximos a tradições religiosas herdadas - principalmente 
catolicismo e espiritismo -, mesmo que sem declaração de filiação, ainda que também sejam frequentes os casos de trânsito religioso - com simpatia pelas religiões mediúnicas. São também os estudantes de Psicologia que se mantêm muito mais afeitos a uma concepção de Deus, de um ser superior ou metafísico - se somarmos os religiosos e os sem religião com crença -, enquanto os estudantes de Ciências Sociais se aproximam mais de concepções imanentes, de uma religiosidade Nova Era em que o sagrado é desterritorializado e dessubstancializado (AMARAL, 2000).

As entrevistas realizadas com esses estudantes nos ajudaram a compreender a relação que se estabelece entre religiosidade e o contexto universitário - que pode gerar desafios à manutenção de um vínculo religioso ou, mais raramente, fortalecê-los, ou ainda, em alguns casos, promover uma aproximação de outras religiosidades. Nesse contexto, o espiritismo, a umbanda e o candomblé se mostram mais atrativos aos estudantes. $\mathrm{O}$ espiritismo, com seu individualismo e cientificismo, entre os estudantes de Psicologia, e o candomblé, positivamente associado a um universo de resistência étnica e à tolerância à diversidade sexual entre os estudantes de Ciências Sociais.

Em relação às indicações de intolerância religiosa, deparamo-nos com declarações de constrangimento em relação à forma como são feitas referências religiosas e tecidas críticas a cristãos - especialmente evangélicos - por parte de alguns estudantes e alguns docentes. As indicações são observadas por autodeclarados religiosos e também não religiosos. Nesse ínterim, a tensão entre religião, política e academia se explicita - o que pode ser considerado um dos principais fatores que colaboram para a desinstitucionalização, para uma simpatia por religiosidades em que essa tensão não esteja tão presente, ou para a adesão a práticas não diretamente associadas ao religioso.

Ao mesmo tempo, a menção de intolerância religiosa por parte de estudantes que participaram de nossa pesquisa deve ser entendida aqui como indicativo de tensões em torno de atitudes críticas que se sobressaem em um universo heterogêneo e sensível à questão religiosa. Também deve ser pensada em relação a um contexto mais amplo de acirramento de tensões entre religião, política e academia no Brasil contemporâneo, aspectos que pretendemos desenvolver em outro artigo. 


\section{Referências}

ALMEIDA, Ronaldo de.

(2017). A onda quebrada - evangélicos e conservadorismo. Cadernos Pagu, 50. p. 5-30.

AMARAL, Leila.

(2000) Carnaval da Alma: comunidade, essência e sincretismo, na nova era. Petrópolis, Editora Vozes.

ARIÈS, Philippe.

(1981). História social da criança e da família. Rio de Janeiro, Editora Guanabara.

BURITY, Joanildo; MACHAD0, Maria das Dores. (2014). A ascensão política dos pentecostais no Brasil na avaliação de líderes religiosos. Dados-Revista de Ciências Sociais 57(3). p. 601-631.

(2005). Os votos de Deus: evangélicos, política e eleições no Brasil. Recife, Fundação Joaquim Nabuco / Editora Massangana.

CAMURÇA, Marcelo Ayres.

(2001). Religiosidade Moderna e esclarecida entre os universitários de Juiz de Fora - MG. Debates do NER, Porto Alegre n. 2, p. 34-64.

DUARTE, Luiz Fernando Dias.

(2003). Indivíduo e pessoa na experiência da saúde e da doença. Ciência \& Saúde Coletiva, v. 8. p. 173-183.

CHAMPION, Françoise.

(2001). Constituição e transformação da aliança ciência-religião na nebulosa místicoesotérica. Religião e Sociedade, v. 18, n. 01, p. 25-43.

FRESTON, Paul.

(2006). Religião e política, sim igreja e estado, não: os evangélicos e a participação política. Viçosa, Ultimato.

FREUD, Sigmund.

(1997). o futuro de uma ilusão. Rio de Janeiro, Imago.
GEERTZ, Clifford.

(2001). Anti-antirrelativismo. In: Nova luz sobre a antropologia. Rio de Janeiro, Zahar.

HERVIEU-LEGER, Daniele.

(2008). 0 peregrino e o convertido: religião em movimento. Petrópolis, Vozes.

LATOUR, Bruno.

(1994). Jamais fomos modernos. São Paulo, Editora 34.

LEWGOY, Bernardo.

(2001a). Secularismo e espiritismo nas Ciências Sociais: discutindo os resultados da UFRGS. Debates do NER, Porto Alegre, n. 2. p. 62-74.

(2001b). Chico Xavier e a cultura brasileira. Revista de Antropologia, v. 44, n. 1, p. 53-116.

(2000). Os espiritas e as letras: um estudo antropológico sobre cultura escrita e oralidade no espiritismo kardecista. Tese de doutorado apresentada a Universidade de São Paulo.

MACHADO, Maria das Dores.

(2006). Política e religião: a participação dos evangélicos nas eleições. Rio de Janeiro, FGV Editora.

NOVAES, Regina.

(2013). Jovens sem religião: sinais de outros tempos. In: TEIXEIRA, Faustino; MENEZES, Renata (org.); Religiões em movimento: 0 Censo de 2010. Petrópolis, Vozes.

(2012). Juventude, religião e espaço público: exemplos "bons pra pensar" tempos e sinais. Religião e Sociedade, Rio de Janeiro, n. 32, p. 184-208.

(2007). Juventude e sociedade: jogos de espelhos, sentimentos, percepções e demandas por direitos e políticas públicas. Revista Sociologia Especial: ciência e vida. 
(2006). Os jovens, os ventos secularizantes e o espírito do tempo. As Religiões no Brasil: continuidades e rupturas. Petrópolis, Vozes.

(2001). Juventude e religião: marcos geracionais e novas modalidades sincréticas. In: SANCHIS, Pierre (Org.). Fiéis \& Cidadãos. Percursos de Sincretismo no Brasil. Rio de Janeiro: Eduerj.

(1994). Religião e política: sincretismos entre alunos de Ciências Sociais. Comunicações do ISER, Rio de Janeiro, n. 45, p. 62-74.

MACHAD0, Maria das Dores; MELLO, Cecília Campello.

(2002). Jovens do Rio: circuitos, crenças e acessos. Comunicações do ISER, Rio de Janeiro, n. 57.

ORO, Ari Pedro.

(2003). A política da Igreja Universal e seus reflexos nos campos religioso e político brasileiros. Revista brasileira de Ciências Sociais 53(18):53-69.

OR0, Ari Pedro; MEIRELLES, Mauro.

(2010). Brazilian University Students And Religion. In: Annual Review of the Sociology of Religion. Leiden, Boston, Brill.

SANCHIS, Pierre.

(2001). Desencanto e formas contemporâneas do religioso. Ciências Sociais e Religião, v. 3, n. 3. p. 27-43.

STEIL, Carlos Alberto; ALVES, Daniel; HERRERA, Sonia.

(2001). Religião e Política entre os alunos de Ciências Sociais: um perfil. Debates do NER, Porto Alegre, n. 2. p. 62-74.
SILVA, Vagner G.

(2007). Intolerância Religiosa: impactos do neopentecostalismo no campo religioso. São Paulo, EdUSP.

TAVARES, Fátima; CAMURÇA, Marcelo.

(2009). Juventudes e religião no Brasil: uma revisão bibliográfica. In: Léa Pereza; Fátima Tavares; Marcelo Camurça (Orgs.); Ser jovem em Minas Gerais: religião, cultura e política. Belo Horizonte, Argvmentvum.

VALLE-HOLLINGER, Adriana; SIQUEIRA， Deis; HOLLINGER, Franz.

(2002). Religião e esoterismo entre estudantes: um estudo comparado internacional. Religião e Sociedade, v. 22, n. 2. p. 115-134.

VELH0, Gilberto.

(1981). Individualismo ecultura: Notas para uma Antropologia da Sociedade Contemporânea. Rio de Janeiro, Zahar Editores.

VITAL, Christina; LOPES, Paulo Victor Leite. (2013). Religião e política: uma análise da atuação de parlamentares evangélicos sobre direitos das mulheres e de LGBTs no Brasil. Rio de Janeiro, Fundação Heinrich Böll.

VITAL, Christina; Lopes, Paulo Victor Leite; LUI, Janayna.

(2017). Religião e Política: medos sociais, extremismo religioso e as eleições 2014. Rio de Janeiro, Fundação Heinrich Böll / Instituto de Estudos das Religiões.

\section{Recebido em}

abril de 2018

Aprovado em

novembro de 2018 